\title{
Reduction in Friction and Wear of Alumina Surfaces as Assisted with Surface- Adsorbing Polymers in Aqueous Solutions
}

\author{
Røn, Troels; Lee, Seunghwan
}

Published in:

Wear

Link to article, DOI:

10.1016/j.wear.2016.09.025

Publication date:

2016

Document Version

Peer reviewed version

Link back to DTU Orbit

Citation (APA):

Røn, T., \& Lee, S. (2016). Reduction in Friction and Wear of Alumina Surfaces as Assisted with SurfaceAdsorbing Polymers in Aqueous Solutions. Wear, 368-369, 296-303. https://doi.org/10.1016/j.wear.2016.09.025

\section{General rights}

Copyright and moral rights for the publications made accessible in the public portal are retained by the authors and/or other copyright owners and it is a condition of accessing publications that users recognise and abide by the legal requirements associated with these rights.

- Users may download and print one copy of any publication from the public portal for the purpose of private study or research.

- You may not further distribute the material or use it for any profit-making activity or commercial gain

- You may freely distribute the URL identifying the publication in the public portal 


\title{
Reduction in Friction and Wear of Alumina
}

\section{Surfaces as Assisted with Surface-Adsorbing}

\section{Polymers in Aqueous Solutions}

\author{
Troels Røn and Seunghwan Lee* \\ Department of Mechanical Engineering, Technical University of Denmark, DK-2800 Kgs. Lyngby, \\ Denmark
}

*Corresponding author: $\underline{\text { seele@,mek.dtu.dk }}$

Key words: alumina, poly(acrylic acid) (PAA), aqueous lubrication, polyanion, polycation 


\begin{abstract}
We have investigated the aqueous lubricating effects of various polymers for the sliding contacts of self-mated alumina surfaces in neutral aqueous environment. Given that isoelectric point (IEP) of alumina is ca. $\mathrm{pH}$ 9, polyanions can readily adsorb onto alumina surface at neutral $\mathrm{pH}$ via electrostatic attraction and form a protective layer. For example, polyacrylic acid (PAA) showed a reduction in coefficient of friction by ca. $28 \%$ and wear rate by $50 \%$ at a concentration of 10 $\mathrm{mg} / \mathrm{mL}$ in PBS solution compared to polymer-free buffer solution. This effect was comparable to reported lubricating effects at moderately acidic and or alkaline $\mathrm{pH}$ conditions via electrostatic repulsion between opposing bare alumina surfaces. Interestingly, polycations, such as (polyallylamine hydrochloride) (PAH) or branched poly(ethylene imine) (b-PEI) have also shown effective surface adsorption and lubrication at neutral $\mathrm{pH}$, when phosphates $\left(\mathrm{HPO}_{4}{ }^{2-}\right)$ are present to mediate the bonding between polycations and positively charged alumina. The present study thus provides various routes to lubricate alumina surfaces in aqueous environment by means of surface adsorbing polymeric additives without shifting from neutral $\mathrm{pH}$.
\end{abstract}




\section{Introduction}

Ceramics have many favorable properties for tribological applications, such as high thermal stability, high abrasion resistance, low deformability, and corrosion resistance [1-4]. In particular, corrosion immunity of ceramics allows them to be applicable as bearing materials under circumstances where exposure of tribosystems to water is unavoidable, such as in marine applications [5-8], high humidity [9, 10], or biomedical applications [11, 12]. Moreover, water can be employed as base lubricant for ceramic materials in engineering bearing systems [13-21]. An outstanding example is the lubrication of silicon nitride with distilled water; the coefficient of friction, $\mu$, can be reduced from $\mu \approx 0.7$ to $\mu \leq 0.002$ with the increase of sliding speed from 2 $\mathrm{mm} / \mathrm{s}$ to ca. $65 \mathrm{~mm} / \mathrm{s}$ [13-15], which was attributed to favorable tribochemical reactions to generate extremely smooth surfaces and onset of hydrodynamic lubrication. However, this approach is applicable only for a few ceramic materials and under limited conditions, namely high speeds and high loads $[16,17]$. More broadly applicable methods to improve the aqueous lubrication properties of ceramics are highly desirable. For example, dispersion of surface-active additives in base stock is a universal approach to reduce friction and wear for oil-based lubricants, and it can be applied to aqueous lubricants as well. Previous studies of employing ionic liquids $[22,23]$ or polycationicpolyethylene glycol copolymer, poly(L-lysine)-graft-poly(ethylene glycol) (PLL-g-PEG) [24], as additives have shown improved boundary lubrication properties for silicon nitrides in neutral $\mathrm{pH}$ aqueous solutions.

In this study, we are particularly interested in aqueous lubrication of alumina. In general, the friction forces of alumina-based tribosystems are known to be reduced as lubricated with water, but its efficacy is not significant, especially in low speed regime $[17,25]$. This is because, unlike the case of silicon nitride mentioned above, favorable tribochemical reaction to initiate surface smoothening does not readily occur because of the high mechanical and chemical stability of 
alumina. Novak and Kalin have reported that self-mated sliding of alumina displays particularly low wear rates due to electrostatic repulsion between either positively $(\mathrm{pH}<8)$ or negatively $(\mathrm{at} \mathrm{pH}>9)$ charged surfaces [26], given the IEP of alumina is at ca. $\mathrm{pH} 8.8$ [27]. Thus, superior tribological performance, i.e. lower friction and wear, is expected at either at acidic or alkaline conditions. At too high or low $\mathrm{pH}$ conditions $(\mathrm{pH} \leq 1$ or $\geq 13)$, however, wear and surface smoothening via tribochemical reactions can be activated [26,28,29]. Electrostatic repulsion between opposing alumina surfaces at moderately acidic and alkaline condition can contribute to lower the interfacial friction forces too. Nevertheless, non-neutral $\mathrm{pH}$ is not a favorable means of aqueous lubrication. We conjecture that surface-adsorbing polymeric additives, which have shown to be effective in reducing friction and wear for many other tribological systems [30-32], can be employed to lubricate alumina surfaces at neutral $\mathrm{pH}$ condition too. As alumina is known to display exceptionally high isoelectric point (IEP) of $\mathrm{pH}>8$ among oxide ceramics [28], its surface is positively charged in neutral aqueous solution. Thus, polyanions or copolymers with anionic anchoring units can adsorb onto alumina surfaces via electrostatic attraction and potentially act as boundary lubricant additive [33-35] and can further modify the surface potential and tribological properties [36]. In this study, we demonstrate that negatively charged polyacrylic acid (PAA) or PAA-based copolymers indeed adsorb and lubricate alumina surfaces in neutral aqueous environment. Moreover, not only polyanionic macromolecules, but also polycationic macromolecules can lubricate alumina surfaces in neutral $\mathrm{pH}$ aqueous solutions when divalent phosphate salts are further employed to mediate the linking polycationic macromolecules to alumina surfaces.

\section{Materials and Methods}

\subsection{Alumina balls and disks}


$6 \mathrm{~mm}$ diameter alumina balls (1365 Vickers Hardness (13.4 GPa), Young Modulus of $370 \mathrm{GPa}$, Ultimate tensile strength $300 \mathrm{MPa}$, Poisson's ratio 0.22) were obtained from Boca Bearings (Boynton Beach, FL). 42 mm diameter alumina (>99.6\%) disks of 1440 Vickers hardness (14.1 GPa) were purchased from Graphitestore.com, Inc. (Lexington, IL).

\subsection{Polymers and formulation of aqueous lubricants}

Poly(acrylic acid) (PAA(5.1 kDa)), PAA(250 kDa), poly(allyl amine hydrochloride) (PAH(17 $\mathrm{kDa})$ ), branched poly(ethylene imine) (b-PEI (800 Da)), poly(vinyl alcohol) (PVA(9 kDa)), poly(ethylene glycol) (PEG(5 kDa)), poly(sodium 4-styrenesulfonate) (PSS $70 \mathrm{kDa})$, and bovine submaxillary mucin (BSM) were all purchased from Sigma-Aldrich (Brøndby, Denmark) and used without further purification. The numbers in the brackets after the acronyms of the polymers represent the molecular weights. BSM is an amphiphilic biomacromolecule with reported molecular of 5-20 MDa [37]. BSM was purchased from Sigma Aldrich (Type I-S) too and used without further purification. Poly(acrylic acid)-graft-poly(ethylene glycol) (10 grafted PEG (1.8 kDa) side chains on a PAA $(8.0 \mathrm{kDa})$ backbone and PDI 1.8) was purchased from Polymer Sources Inc. (Montreal, Canada). Phosphate buffered saline (PBS) was prepared as buffer (pH 7.4) by dissolving PBS tabs from VWR (BDH Prolabo) in MilliQ water $(18 \mathrm{M} \Omega \cdot \mathrm{cm})$. Polymers or protein were initially dissolved at higher concentration in $\mathrm{PBS}$ and $\mathrm{pH}$ was adjusted by $\mathrm{HCl}$ (aq.) or $\mathrm{NaOH}($ aq.) to achieve $\mathrm{pH} 7.4$ or 2.0 . Then the targeted concentrate of polymer or protein was obtained by addition of PBS.

\section{$2.3 X$-ray photoelectron spectroscopy (XPS)}

A K-Alpha XPS with included flood gun from Thermo Scientific (Al K $\alpha$ radiation source) was used for the surface chemical analysis of the alumina samples before and after exposing to polymer or 
protein solutions. Thermo Avantage software v. 5.932 was used for the elemental data analysis.

Two spots were measured for mean and standard deviation calculations. Alumina disks were polished with silicon carbide sand paper (Grit 1000) and cleaned by ultra-sonication in Hellmanex (1 vol\%) surfactant aqueous solution for $15 \mathrm{~min}$, then in PBS for $15 \mathrm{~min}$, and finally in MilliQ water for $15 \mathrm{~min}$. After drying with nitrogen, the alumina disks were submerged or covered with buffer or $10 \mathrm{mg} / \mathrm{mL}$ polymer or protein solutions for $30 \mathrm{~s}$. Then, the alumina disk was dipped in MilliQ water to gently remove non-adsorbed species, and finally blown-dried with nitrogen before XPS measurements commenced.

\subsection{Friction and wear measurements}

Aqueous lubricating properties of polymers for alumina-alumina interfaces were examined with a pin-on-disk tribometer, by employing $6 \mathrm{~mm}$ diameter alumina sphere sliding on a $3 \mathrm{~mm}$ thick alumina disk with $10 \mathrm{~N}$ load (dead weight) if not stated otherwise. The mechanical and surface properties of the tribosystems are presented in Table 1.

Table 1. Mechanical and surface properties of alumina-alumina tribological interface.

\begin{tabular}{|c|c|c|c|c|c|c|}
\hline \multirow{2}{*}{ Material } & \multirow{2}{*}{$\begin{array}{l}\text { Young's } \\
\text { modulus } \\
\text { (GPa) }\end{array}$} & \multirow{2}{*}{$\begin{array}{l}\text { Poisson's } \\
\text { Ratio }\end{array}$} & \multirow{2}{*}{$\begin{array}{l}\text { Hardness } \\
\text { (GPa) }\end{array}$} & \multicolumn{2}{|c|}{ Roughness, $R_{q},(\mathrm{~nm})$} & \multirow{2}{*}{$\begin{array}{l}\text { Pressure } \\
(\mathrm{MPa}) \text { at } \\
10 \mathrm{~N} \text { load }\end{array}$} \\
\hline & & & & Disk & Ball & \\
\hline \multirow[t]{3}{*}{ Alumina } & 370 & 0.22 & 13.4 & 1780 & 14.3 & $\begin{array}{l}1340^{\mathrm{a}} \\
\text { (Hertzian) }\end{array}$ \\
\hline & & & & Worn: & Worn: & \\
\hline & & & & 144 & 29.1 & $\begin{array}{l}342^{\mathrm{b}}, 17.1^{\mathrm{c}} \\
\text { (Rough/worn at injection) }\end{array}$ \\
\hline
\end{tabular}

${ }^{a}$ Mininum pressure assuming smooth sphere on smooth plane contact. Real contact pressure is probably higher due to roughness. ${ }^{b}$ Calculated as flat-flat contact and assuming only contact at the top $25 \%$ of asperity height distribution, i.e. real area is $5 \%$ of apparent contact area. Pressures at local asperity contacts may be much higher. See also footnote and Greenwood and Williamson [38]. ' If the contact is perfect smooth flat-on-flat.

A standard procedure to assess the lubricating properties of a polymer is as follows: firstly, a sliding contact between alumina-alumina pair was allowed on a fixed track for 5,000 laps at $50 \mathrm{~mm} / \mathrm{s}$ in 
polymer-free buffer solution. Then, a concentrate additive solution $(30 \mathrm{mg} / \mathrm{mL})$ was added to the buffer solution to afford a final concentration of $10 \mathrm{mg} / \mathrm{mL}$, and the sliding contact was continued for another 5,000 laps. The decrease in the friction coefficient ( $\mu=$ friction force/load) was quantified by taking the difference in $\mu$ values before and after addition of the polymers, i.e. $\%$ reduction $=\left\{\left(\mu_{\text {buffer }}-\mu_{\text {polymer }}\right) / \mu_{\text {buffer }}\right\} \times 100 \%$, where $\mu_{\text {buffer }}$ is the average value over the first 5,000 laps and $\mu_{\text {polymer }}$ is the average value over 5,200-6,200 laps. A friction drop of $2.5 \%$ was observed to occur on average for 5200-6200 laps when omitting addition of the polymers, thus this decrease in friction was subtracted in the calculation of \% reduction in $\mu$ values. The initial 200 laps after the injection of polymer solution was excluded as $\mu$ values were generally not stabilized in that range. The results of average \% reduction in $\mu$ values and standard deviations are shown in the legends of friction data plots (Figure 2, 3, and 4). Control experiments include the sliding contacts at lower sliding speeds $(1 \mathrm{~mm} / \mathrm{s}$ and $10 \mathrm{~mm} / \mathrm{s})$, where the alumina-alumina pair was slid for $30 \mathrm{~min}$ before injection and continued for another 30 min after injection. In this case, $\mu_{\text {polymer values were obtained }}$ from the range of time $=2,200-3,000 \mathrm{~s}$. Wear tests were carried out by performing sliding contacts under the respective conditions or lubricant $(10 \mathrm{mg} / \mathrm{mL})$ from the beginning of the experiment. The volume loss was characterized by examining the wear spot of alumina sphere from optical microscopic images. The base buffer was PBS at $\mathrm{pH} 7.4$ if not stated otherwise.

\section{Results and Discussions}

\subsection{Adsorption of polymeric additives onto alumina surface}

In this study, we have employed XPS to characterize the adsorption properties of various polymers onto alumina surfaces. Due to unexpected lubricating performance of polycations, such as b-PEI (800 Da) and PAH (17 kDa), to be addressed below (Section 3.5), their adsorption properties onto alumina surface was also studied by XPS. Dipping time of alumina disk into the polymer solutions 
was limited to 30 seconds because the friction experiments (see sections below) indicated that adsorption of the additives onto alumina disk progressed very rapidly, namely on the level of a few seconds. More importantly, in the present study, the adsorption properties of the additives in a short time scale are more relevant to their lubricating properties; cyclic tribological stress applied in the pin-on-disk tribometry experiments enforces the initially adsorbed polymeric additives to desorb and the surface desorption/adsorption is continuously re-established in a very short time scale. Figure 1 displays the elemental surface analysis of the alumina disks after dipping in $10 \mathrm{mg} / \mathrm{mL}$ solutions of the polymeric additives, then washing and blown-drying with nitrogen.

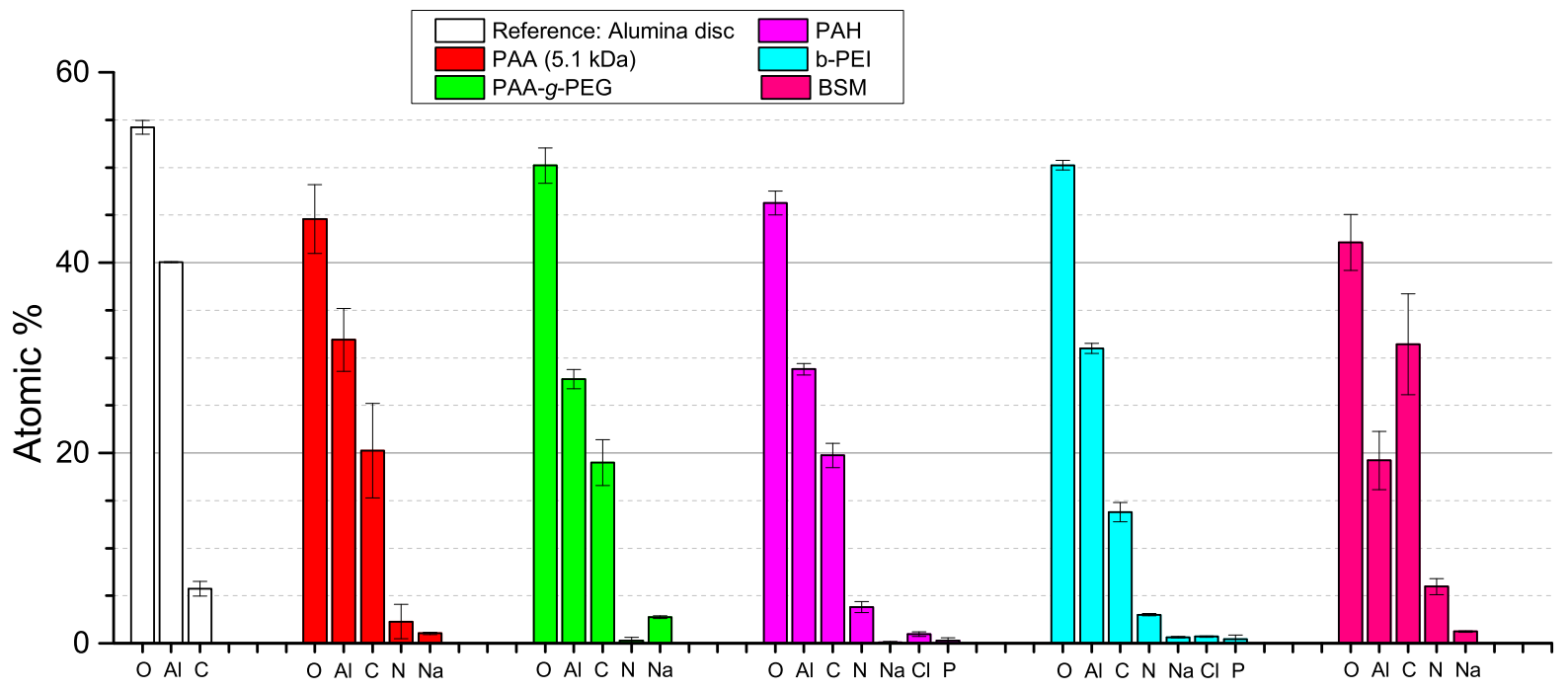

Figure 1. XPS surface elemental analysis of alumina disk after dipping in polymer or protein solution $(10 \mathrm{mg} / \mathrm{mL})$ for $30 \mathrm{sec}$.

The reference "bare" alumina disk, immersed in buffer solution, showed $5.7 \pm 0.8 \%$ carbon content, originated presumably from airborne carbon species $[39,40]$. In all cases of immersion into polymeric additive solutions, the carbon contents were observed to be higher than the reference. For instance, PAA(5.1 kDa), PAA-g-PEG, and PAH (17 kDa) showed the carbon content of ca. 20\% and were not statistically distinguishable from each other. In contrast, b-PEI (800 Da) and BSM 
showed somewhat lower (ca. 15\%) or higher (ca. 31\%) carbon contents. PAA(5.1 kDa) and PAA-gPEG showed a trace amount of nitrogen $(2.3 \pm 1.8 \%$ and $0.3 \pm 0.3 \%$, respectively), for which the origin is not clear. Nitrogen was also observed from PAH (17 kDa) and b-PEI (800 Da) of $3.8 \pm$ $0.6 \%$ and $3.0 \pm 0.1 \%$, respectively, which most probably originate from their nitrogen-containing repeating units, $\left(-\mathrm{CH}_{2} \mathrm{CH}-\mathrm{CH}_{2} \mathrm{NH}_{2}\right)_{\mathrm{n}}$ and $\left(-\mathrm{CH}_{2} \mathrm{CH}_{2} \mathrm{NH}-\right)_{\mathrm{n}}$. However, the carbon-to-nitrogen \% ratios were 5.2 and 4.6 for PAH (17 kDa) and b-PEI (800 Da), respectively, thus were higher than their net formulas. This discrepancy is ascribed to the additional adsorbing airborne carbon species as mentioned above. The nitrogen content was highest for BSM $(6.0 \pm 0.8 \%)$ among the additives, originating from its proteinaceous structure. Lastly, sodium was present in PAA (5.1 kDa) and PAA-g-PEG seemingly as counter ion $\left(\mathrm{Na}^{+}\right)$to carboxylate groups. Likewise, chlorine was observed from PAH (17 kDa) and b-PEI (800 Da), probably as counter ion $\left(\mathrm{Cl}^{-}\right)$for the positively $\mathrm{NH}_{3}{ }^{+}$and $-\mathrm{NH}_{2}{ }^{+}$- groups. Phosphorus was also observed from PAH (17 kDa) and b-PEI (800 Da). While it is not certain if phosphates $\left(\mathrm{H}_{2} \mathrm{PO}_{4}^{-}, \mathrm{HPO}_{4}{ }^{2-}\right)$ in $\mathrm{PBS}$ act as counter ions for the polycations, divalent $\mathrm{HPO}_{4}{ }^{2-}$ may act as chelating salt-bridge between amine groups and the positively charged alumina. See more discussion on this subject in Section 3.4. Presence of $\mathrm{PO}_{4}{ }^{3-}$ is not realistic given the $\mathrm{p} K_{\mathrm{a}}$ of $\mathrm{HPO}_{4}{ }^{2-}$ is 12.3 [41].

Adsorption of PAA onto alumina surfaces is known to be achieved predominantly via hydrogen bonding at $\mathrm{pH}<4$ and electrostatic attraction at $\mathrm{pH}=5.0-9.2$ [35]. Several previous studies have reported facile adsorption of PAA onto alumina surface, within the range of 0.04-0.3 $\mathrm{mg} \cdot \mathrm{m}^{-2}$, depending on solution $\mathrm{pH}$, molecular weight, and bulk concentration [33-35, 42]. Nevertheless, nearly all of these studies were performed on alumina colloidal suspension whereas the information on the adsorbed amount of PAA on planar alumina surface is very rare to date due to a number of technical problems. In this study too, adsorption properties onto alumina disk by XPS (Figure 1) were focused on the comparison of relative adsorbed amount among the polymeric 
additives. As carbon and oxygen signals have multiple origins, we judged that it would be most straightforward to determine the relative adsorbed mass from the reduction in aluminum element signal upon exposure to polymer solutions. The results show that BSM adsorbed to the largest extent onto alumina in that the atomic \% signal reduction is the largest with respect to bare alumina disk, namely a drop from $40.1 \pm 0.03 \%$ to $19.2 \pm 3.0 \%$. In the same context, the relative adsorbed amounts were estimated to be in the order BSM $>$ PAA-g-PEG $\geq$ PAH $(17 \mathrm{kDa}) \geq \mathrm{b}$-PEI $(800 \mathrm{Da}) \geq$ PAA(5.1 kDa). However, considering the overlapped standard deviations among the aluminum signals for the polymers as shown in Figure 1, the magnitude of reduction in aluminum element is statistically comparable to each other. Moreover, the fact that aluminum element signal is reduced only to a half in all cases upon exposure to polymeric additives and it still comprises ca. $20 \%$ of the total signals indicates that a thick polymer layer was not formed on the alumina disk surface. Instead, the polymeric layers were either very thin or bare alumina surface was still exposed to a certain extent.

\subsection{Lubrication by PAA}

Figure 2 shows the frictional responses of the sliding contacts of alumina-alumina interface in aqueous buffer to addition of various polyanions.

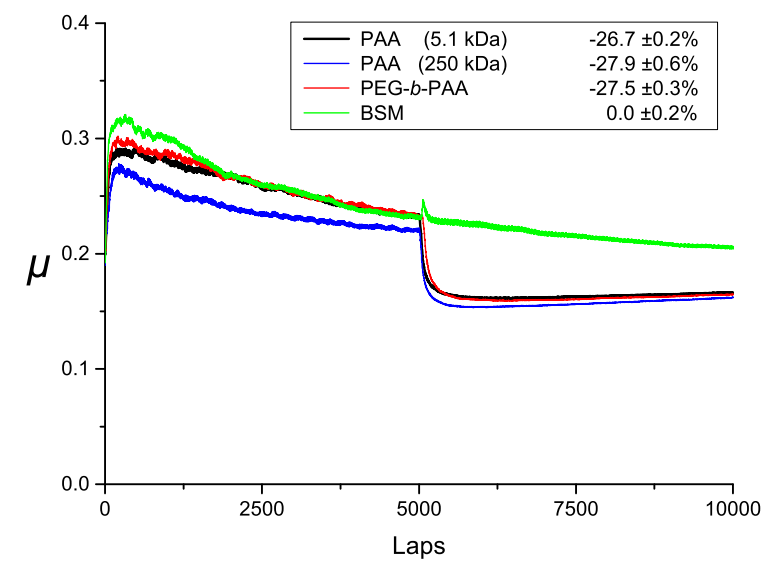


Figure 2: Pin-on-disk tribometry of alumina-alumina interface in PBS ( $\mathrm{pH} 7.4$ ) with injection of polyanions or protein lubricant additives after 5000 laps. In legend, the percentage decrease designates the changes in average $\mu$ values (laps 5200-6200) relative to those before injection. Final concentration of PAA(5.1 kDa), PAA(250 kDa) PAA-g-PEG, and BSM was $10 \mathrm{mg} / \mathrm{mL}$.

In these experiments, the lubricating effect was quantified by calculating $\%$ reduction in $\mu$ values after adding concentrated additive solution to the tribological contacts in buffer for individual measurement (section 2.4). This was mainly because the sliding contacts of alumina-alumina interface in buffer did not provide the identical $\mu$ values and thus raw data may mislead the lubricating efficacy when $\mu$ are directly compared in absolute values.

Addition of PAA led to immediate (less than $10 \mathrm{~s}$ after addition) decrease in $\mu$ values, reflecting fast adsorption kinetics of PAA onto alumina surface. PAA $(5.1 \mathrm{kDa})$ clearly showed an ability to lower the friction of the sliding alumina-alumina contact by showing $26.7 \pm 0.2 \%$ reduction in the $\mu$ values. $\operatorname{PAA}(250 \mathrm{kDa})$ was also tested in order to investigate the influence of molecular weight, but the relative decease in $\mu$ values was comparable to that for $\operatorname{PAA}(5.1 \mathrm{kDa})$, namely $27.9 \pm 0.6 \%$ (Figure 2). One could expect that the polymers with higher molecular weight would provide higher adsorption stability, and thus more effective lubricity, as long as the chain conformation on surface of both PAAs remain ideally flat-lying [34, 43]. As a control experiment, sodium acetate $(10 \mathrm{mg} / \mathrm{mL}$ in the final concentration), corresponding to the monomeric units of PAA, was injected, but it did not induce any friction lowering effect on the sliding alumina-alumina interface (data not shown). This means that the lubricating effect of PAA(5.1 kDa) was not achieved simply via the adsorption of monomeric acrylic acid units to alumina surface, but some degree of polymerization was needed to enhance the anchoring strength of the adsorbate. On the other hand, linear homopolymers show increasing tendency to form loop conformation with increasing molecular weight on adsorbing solid surfaces. In turn, this can lead to bridging between 
the two opposing surfaces, and may contribute to increased adhesion and friction [44]. Nearly identical lubricating effects observed from the two PAAs in this study may be explained by that the difference in the molecular weight of the two PAA is not large enough to induce significant conformational changes or improved adsorption stability. Alternatively, it is also likely that extremely high contact pressure exerted on alumina-alumina interface may have suppressed any possible changes arising from the molecular weight (chain length) of PAA. If electrostatic repulsion between alumina surfaces with the same charges at moderate acid or alkaline condition provides an effective lubrication as proposed by Novak and Kalin [26,28,29], adsorption of PAA onto positively charged alumina may reduce the electrostatic repulsion effect by charge compensation. The clear reduction in $\mu$ values by adsorption of PAAs onto alumina surface thus implies that suppression of direct contact between bare alumina surfaces by an organic layer overwhelms the reduced electrostatic repulsion, and eventually more beneficial for aqueous lubrication of alumina-alumina interface.

The initiation of changes in friction forces upon addition of the concentrated PAA solution occurred usually in less than $10 \mathrm{~s}$. However, it should be noted that this fast frictional responses is largely indebted from the relatively high concentration of the added PAA solution (final concentration, $10 \mathrm{mg} / \mathrm{mL}$ ). We propose that the concentration gradient is an important parameter to determine the efficacy of lubrication by PAA in this study; as the adsorption of PAA on alumina surface is primarily based on physisorption (electrostatic attraction), the films are easily removed by tribostress encountered in tribometry experiment. Thus, PAA layers on alumina surface can be sustained only when ample amount of PAA is available in bulk solution and thus continuous fast readsorption ("self-healing") can take place [45]. A control experiment with a lower concentration (e.g. $1 \mathrm{mg} / \mathrm{mL}$ ) of PAA $(5.1 \mathrm{kDa})$, for example, showed only a $4.5 \%$ reduction in $\mu$ values (Figure S1, Supplementary Material). 
While all the experiments with PAA discussed above were conducted under $10 \mathrm{~N}$ load, a control experiment with PAA(5.1 kDa) as shown in Figure 2, yet under a higher load $(25 \mathrm{~N})$ was carried out. Even though the $\mu$ values, both before and after injecting PAA(5.1 kDa) solution (30 $\mathrm{mg} / \mathrm{mL})$ into buffer solution, were somewhat higher, the $\%$ reduction $(28.2 \%)$ was comparable to that of the $10 \mathrm{~N}$ case. This observation suggests that the lubricating performance by PAA(5.1 kDa) might be effective even for a higher load range and deserves further investigation in the future. The results are presented in Figure S2, Supplementary Material.

PSS has previously shown to adsorb onto alumina, thus it was conjectured that such a strong polyelectrolyte would provide lubricity to the sliding alumina contact as well [46]. However, when $10 \mathrm{mg} / \mathrm{mL}$ PSS (70 kDa) in PBS pH 7.4 was injected only a marginally drop (4.2 $\pm 0.4 \%)$ in friction was observed (Figure S3, Supplementary Material). Thus, the interaction strength between the alumina and negative benzene-sulfonate groups are not as strong as to the $\mathrm{PAA}^{-}$, indicating that PAA-alumina have characteristic electrostatic static bonding.

\subsection{Lubrication by PAA-g-PEG and BSM}

Following the effective performance of PAA as polymeric additive to lubricate the sliding interface of alumina-alumina, a graft copolymer, namely PAA-g-PEG, was employed for comparison. Two or more constituent polymers in a copolymer may display selective solubility to solvent and/or affinity to the substrates. In the case of PAA-g-PEG, while both PEG and PAA show excellent solubility in water, PAA only shows effective affinity to alumina surface at neutral $\mathrm{pH}$ via electrostatic attraction. Thus, PAA backbone in PAA-g-PEG copolymer is expected to act as anchor onto alumina surface, whereas grafted PEG side chains stretch out to bulk water to attract solvent (water) and can possibly improve the lubricating capabilities compared to PAA alone [47, 48]. The results showed that PAA-g-PEG graft the reduction in the $\mu$ values was $27.5 \pm 0.3 \%$ (Figure 3), 
which is comparable to that by $\operatorname{PAA}(5.1 \mathrm{kDa})$ and no particular improvement was observed in the lubricating properties.

For the particular PAA-g-PEG in this study, a low grafting density of PEG chains along the $\operatorname{PAA}(8 \mathrm{kDa})$ backbone (one per every eleven acrylic acid monomer units) may hinder extensive stretching of PEG side chains $(1.8 \mathrm{kDa})$ to form "brush-like" conformation. Nevertheless, nearly identical lubricating effect of the PAA-g-PEG with PAA $(5.1 \mathrm{kDa})$ cannot be ascribed to low grafting density of PEG chains only, as some extent of improvement was reported from steel-glass interface under a similar condition [47]. We propose that extremely high contact pressure of alumina-alumina interface (ca. $342 \mathrm{MPa}$ in estimated contact pressure (Table 1) may have overwhelmed their pressure-opposing effects expected from the osmotic pressure. The contact pressure exerted on the contact area is more than one order of magnitude larger than the maximum osmotic pressure achievable by polymer brushes that are commonly available, i.e. ca. $15-25 \mathrm{MPa}$ as reported in literature [49-51].

BSM has previously shown facile adsorption and lubrication of non-polar surfaces $[52,53]$, but corresponding studies on ionic surfaces are scarce to date. While the XPS data in the previous section confirmed the facile adsorption of BSM onto alumina surface, addition of BSM did not give any lubricating effect. Inefficient and inferior lubricating properties of BSM to PAA or PAA-g-PEG could be due to lower charge density on BSM, which may lead to relatively weaker adsorption strength on alumina surface and lower hydration.

\subsection{Lubrication by polycationic additives}

It was most interesting to observe that the two polycations in this study, namely PAH (17 kDa) and b-PEI (800 Da), have also provided significant reductions in the $\mu$ values, $28.0 \pm 0.1 \%$ and $32.6 \pm$ 
$0.1 \%$, respectively, upon addition to the sliding contacts of alumina-alumina interface, similarly with the polyanions (Figure 3).

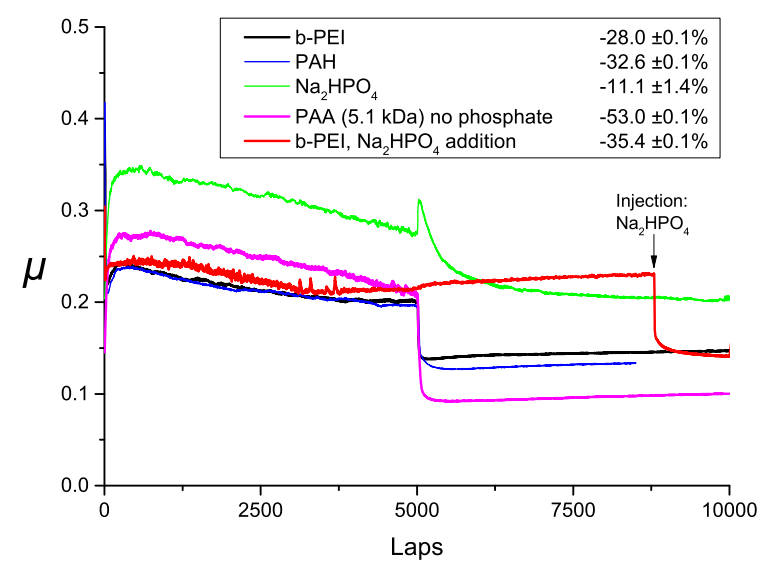

Figure 3: Pin-on-disk tribometry of alumina-alumina contact with injection of polyelectrolyte or salt lubricant additives after 5000 laps if not stated otherwise. $10 \mathrm{mM} \mathrm{Na}_{2} \mathrm{HPO}_{4}$ was added to aqueous $150 \mathrm{mM} \mathrm{NaCl} \mathrm{pH} 7.4 \mathrm{for}$ samples ' $\mathrm{Na}_{2} \mathrm{HPO}_{4}$ ' and 'b-PEI, $\mathrm{Na}_{2} \mathrm{HPO}_{4}$ addition'. The average $\mu$ values of laps 9200-10,000 were used to assess friction drop for 'b-PEI, $\mathrm{Na}_{2} \mathrm{HPO}_{4}$ addition'. In sample 'PAA $(5.1 \mathrm{kDa})$ no phosphate' the aqueous solution condition was $150 \mathrm{mM}$ $\mathrm{NaCl}$ at $\mathrm{pH} 7.4$.

The lubricating capabilities of polycationic b-PEI (800 Da) and PAH (17 kDa) are consistent with their adsorption properties shown in XPS data (Figure 1) and further support the strong interaction with the positively charged alumina. This is surprising and counter-intuitive from a Coulombic interaction viewpoint as mentioned above. Two possible interaction mechanisms can be proposed for the alumina-polycation interaction. Firstly, hydrogen bonding between the polycations and alumina surface can be strong enough to overcome the electrostatic repulsion between them. $\mathrm{p} K_{\mathrm{a}}$ values of 8.8 and ca. 8.18-9.94 have been reported for PAH and b-PEI, respectively, thus some of the amine repeating units are expected to be non-charged at $\mathrm{pH} 7.4$ and can participate as either hydrogen bonding donor or acceptor [54]. As an indirect way to test this hypothesis, PVA (9-10 $\mathrm{kDa})$ or PEG(5 $\mathrm{kDa})$, representing strong hydrogen bonding donor and receptor, respectively, were 
added to the sliding alumina-alumina contacts $(10 \mathrm{mg} / \mathrm{mL}$ final concentration). Nevertheless, no friction decrease was observed for neither PVA nor PEG (data not shown), which suggests that hydrogen bonding is probably not a major contributing factor. Secondly, phosphate ions from $\mathrm{Na}_{2} \mathrm{HPO}_{4}$ in PBS may act as a mediator between two positively charged substances (polycations and alumina surface). To test this hypothesis, a control experiment was conducted by employing PBS containing $150 \mathrm{mM} \mathrm{NaCl}$ at $\mathrm{pH}$ 7.4, yet excluding phosphates, as base lubricant. Upon addition of b-PEI (800 Da) to the buffer where alumina-alumina sliding contact is taking place, virtually no change in the friction was observed (data in red lines in Figure 3). However, when $\mathrm{Na}_{2} \mathrm{HPO}_{4}(10 \mathrm{mM})$ was further added in the same solution, a clear and immediate decrease in the $\mu$ value by $35.4 \pm 0.1 \%$ was observed. In fact, addition of $\mathrm{Na}_{2} \mathrm{HPO}_{4}(10 \mathrm{mM})$ alone into $150 \mathrm{mM}$ $\mathrm{NaCl}$ water $\mathrm{pH} 7.4$ also resulted in $11.1 \pm 1.4 \%$ reduction in $\mu$ values. Even though the reduction in $\mu$ is not large by $\mathrm{Na}_{2} \mathrm{HPO}_{4}$ alone, this observation confirms a strong affinity of phosphate ions on alumina surface. Moreover, by employing $10 \mathrm{mM}$ HEPES buffer salt with $150 \mathrm{mM} \mathrm{NaCl}$ buffer solution, another common neutral buffer without phosphate as base lubricant, only a minor decrease of $10.0 \pm 2.3 \%$ in $\mu$ value was observed (data not shown) by b-PEI (800 Da) injection. Both control experiments support the critical importance of phosphate ions to induce lubricating effects by the polycations for alumina-alumina interface in neutral buffer solutions.

Based on all the experimental results in this section, we propose that phosphate-mediate adsorption of polycations can occur as schematically shown in Figure 4. Most inorganic aluminum phosphates have very low solubility in water implying strong electrostatic forces between the ions $[55,56]$, hence increasing the stability of the alumina-phosphate salt bridge to polycations even under strong tribostress. Furthermore, both PAH and b-PEI have in other studies were observed to bind to phosphates and form aggregates $[57,58]$. As shown in Figure 3, removing phosphates from the PAA $(5.1 \mathrm{kDa})$ solution increased the friction reduction to $53.0 \pm 0.1 \%$ from $26.7 \pm 0.2 \%$ in the 
buffer, despite the presence of $150 \mathrm{mM} \mathrm{NaCl}$. This suggests adsorption competition between PAA and phosphates, i.e. PAA seemingly can adsorb more strongly - thus affording lower friction when omitting phosphates in solution.

Inspired from the interesting mediator role by phosphate ions, a similar experiment with those shown in Figure 3 was conducted by employing $\mathrm{SO}_{4}{ }^{2-}$ as another divalent salt mediator $\left(\mathrm{Na}_{2} \mathrm{SO}_{4}\right)$. Addition of b-PEI (800 Da) $(10 \mathrm{mg} / \mathrm{mL})$ into the tribocup where alumina-alumina sliding contact is taking place in an aqueous solution $\left(10 \mathrm{mM} \mathrm{Na}_{2} \mathrm{SO}_{4}+150 \mathrm{mM} \mathrm{NaCl}\right)$, however, did not lead to any reduction in $\mu$ values (data not shown). Thus, presently, the unique function as a mediator between polycations and alumina surfaces in neutral aqueous solution should be limited to $\mathrm{Na}_{2} \mathrm{HPO}_{4}$.

\subsection{Lubrication by PAA: at lower speeds, lower loads, and acidic $\mathrm{pH}$}

Figure 4 shows additional experiments to investigate the lubricating properties of PAA $(5.1 \mathrm{kDa})$ at alumina-alumina interface by varying parameters, such as sliding speed, load, and $\mathrm{pH}$ of aqueous solution, from the standard conditions (section 3.3).

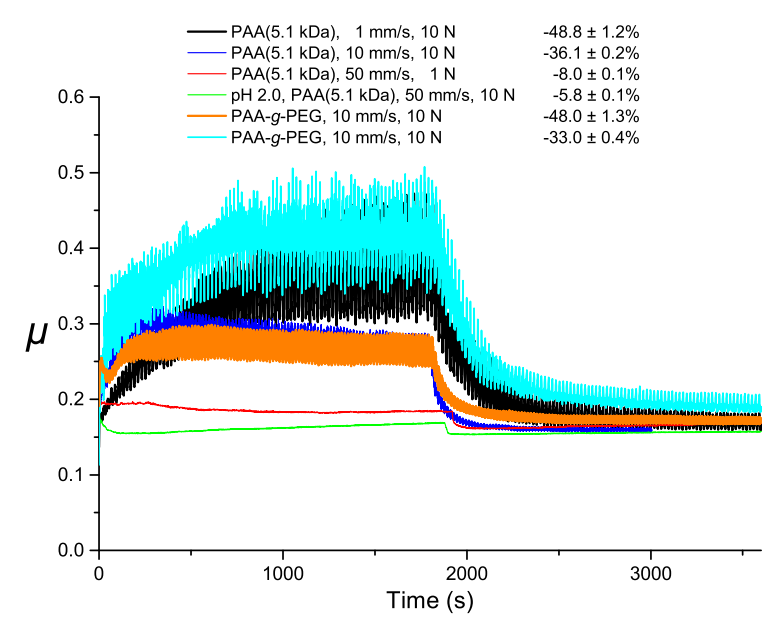

Figure 4. Pin-on-disk tribometry of alumina contact polymer at non-standard conditions for $\mu$ vs. time. Due to different speed for each measurement, the x-axis was plotted in time (s) than laps for better relative comparison. $1900 \mathrm{~s}$ is equal 
to 5000 laps at $50 \mathrm{~mm} / \mathrm{s}$ as plotted in Figure 3. The average $\mu$ values of time $2200-3000 \mathrm{~s}$ was used to assess friction drop. Final concentration of polymer was $10 \mathrm{mg} / \mathrm{mL}$.

For instance, sliding contacts between alumina surfaces at lower linear sliding speeds of $1 \mathrm{~mm} / \mathrm{s}$ or $10 \mathrm{~mm} / \mathrm{s}$ resulted in greater reduction in the $\mu$ values with decreasing speed, namely $48.8 \pm 1.2 \%$ and $38.1 \pm 0.2 \%$, respectively. This is, however, because the $\mu$ values of alumina-alumina interface in buffer solution was gradually increasing with decreasing speed, reaching $\mu=0.35-0.4$ at $1 \mathrm{~mm} / \mathrm{s}$, whereas the $\mu$ values for PAA-lubricated contacts were rather similar at all speeds. In an ideally elastic contact, the coefficient of friction is expected to be inversely proportional to load with a power of $-1 / 3$ [59]. Thus, increasing $\mu$ values with increasing load in the sliding contacts between alumina surfaces imply that some other energy dissipation modes than interfacial friction, such as plastic wear from ploughing/abrasion, are active. The assessment of wear properties is discussed below (see section 3.6). Meanwhile, nearly identical $\mu$ values observed from the alumina-alumina interface as lubricated by PAA $(5.1 \mathrm{kDa})$ solution at both 1 and $10 \mathrm{~N}$ load suggest that the friction lowering effect by PAA $(5.1 \mathrm{kDa})$ is more pronounced under higher contact pressure. Moreover, nearly constant $\mu$ value of ca. 0.17 for the alumina-alumina interface over the speed range of 1 $\mathrm{mm} / \mathrm{s}$ to $50 \mathrm{~mm} / \mathrm{s}$ as lubricated by $\operatorname{PAA}(5.1 \mathrm{kDa})$ is another indication of the prevalence of boundary lubrication.

In order to investigate if protonated, non-charged PAA also shows lubricating effects at the sliding alumina-alumina contact, a pin-on-disk tribometry experiment was performed at $\mathrm{pH} \mathrm{2.} \mathrm{As}$ PAA's $\mathrm{p} K_{\mathrm{a}}$ is reported to be 6.12 , and alumina increases its positive zeta potential with decreasing $\mathrm{pH}$ lower than its isoelectric point, electrostatic attraction between them is nearly impossible at $\mathrm{pH}$ 2.0 [60]. PAA $(5.1 \mathrm{kDa})$ was able to decrease the relative friction by $5.8 \pm 0.1 \%$ at $\mathrm{pH} 2.0$ only, as compared to $26.7 \pm 0.2 \%$ decrease at $\mathrm{pH} 7.4$ in PBS buffer. This suggests that PAA molecules are 
still able to bind to alumina surface in the sliding interface at $\mathrm{pH} 2.0$ to some extent, most likely via hydrogen bonding, but the adsorbed amount is not significant and/or anchoring is not as strong. It is to note that $\mu$ values at $\mathrm{pH} 2.0$ before addition of PAA were already lower than those at $\mathrm{pH} 7.4$ (Figure 5), which can be explained by the repulsion effect between the alumina surfaces at $\mathrm{pH} 2.0$ as suggested by Novak and Kalin $[26,28]$. The larger decrease in $\mu$ values by PAA at pH 7.4 can thus be interpreted to arise from superior adsorption in amount and/or strength via electrostatic interaction between carboxylate groups and $\mathrm{AlO}-\left(\mathrm{OH}_{2}{ }^{+}\right)$.

\subsection{Wear rates of alumina pin}

Lastly, the influence of PAA $(5.1 \mathrm{kDa})$ on the wear properties of alumina-alumina sliding interface was evaluated by comparing the wear rates of alumina pins lubricated with PAA polymer solution (concentration, $10 \mathrm{mg} / \mathrm{mL}$ in PBS) and those with polymer-free buffer solution. Optical microscopic images of wear spots of alumina pins and disks are shown in Figure S4, Supplementary Material (Please also see AFM images of alumina disk before and after wear in Figure S5, Supplementary Material). In order to compare the reduction in wear rates as assisted by the adsorbed PAA vs. electrostatic repulsion [26], a wear experiment was conducted at in polymer-free, buffer at $\mathrm{pH} 2.0$ as well. The results are shown in Figure 5.

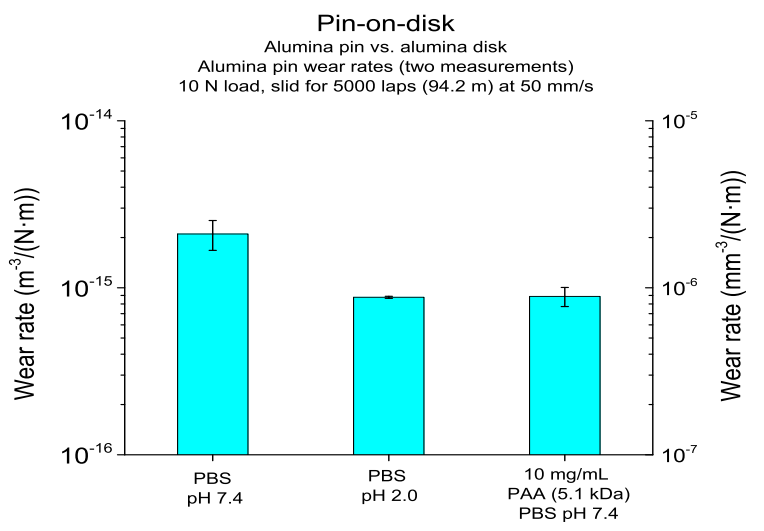


Figure 5. Wear rates of alumina pin caused by sliding against alumina disk at $50 \mathrm{~mm} / \mathrm{s}$ for $94.2 \mathrm{~m}$ (5000 laps).

PAA $(5.1 \mathrm{kDa})$ solution reduced the wear rate of alumina by $50 \%$ compared to buffer at $\mathrm{pH} 7.4$. Furthermore, the magnitude of reduction in the wear rate by $10 \mathrm{mg} / \mathrm{mL}$ of PAA $(5.1 \mathrm{kDa})$ was comparable to that by acidic aqueous solution at $\mathrm{pH}$ 2.0. This is similar to the frictional properties in that alumina-alumina contacts under $10 \mathrm{~N}$ reaching $\mu=0.16-0.17$ when it is lubricated by either

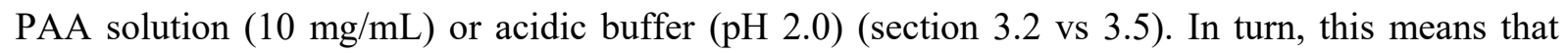
comparable lubricating performance with moderately acidic or alkaline $\mathrm{pH}$ aqueous solutions [26] can be achieved even at $\mathrm{pH} 7.4$ as long as it is assisted by PAA anionic homopolymer. Hence, more complex - and expensive - structures like graft copolymer PEG-g-PAA are not required to afford lubricity and lower wear in self-mated alumina sliding contact.

The impact of alumina wear particles on the subsequent tribological process is debatable; Fischer and Chaiwan reported that wear debris in dry alumina contacts were grinded into fine soft powder, concentrated in surface pits, and did not induce a secondary abrasive wear mechanism. But, it does not necessarily exclude the possible contribution to higher friction and/or if the wear particles bond to injected PAA or PAA-g-PEG, thus influencing both the friction and wear effects in the sliding interface $[61,62]$.

\section{Conclusions}

In this study, we have shown that the friction and wear properties of alumina-based tribosystems in aqueous environment can be readily improved when polyanionic macromolecules are added as surface-adsorbing additives by employing PAA as a principal example. Negatively charged PAA molecules readily adsorb onto positively charged alumina surface at neutral $\mathrm{pH}$ and the high bulk concentration $(10 \mathrm{mg} / \mathrm{mL})$ allows for continuous replenishment of the polymers that are sheared off from the surface due to tribological stress. Due to extremely high contact pressure at the self-mated 
contact between alumina ( $>300 \mathrm{MPa}$ under $10 \mathrm{~N}$ in this study), however, the sliding contacts of alumina-alumina interface in PAA solution were dominated by boundary lubrication and the \% reduction in friction coefficient was saturated at 25-30\% in high-speed regime and ca. 50\% in lowspeed regime, respectively. In the same context, PAA-g-PEG did not provide any further

improvement in the lubrication effect compare to PAA, despite its potential as brush-forming capabilities. It was most interesting to observe that polycationic macromolecules, such as PAH and b-PEI, also lubricated the sliding alumina-alumina interface to a similar extent with PAA. Control experiments have revealed that salt bridging by negatively charged divalent phosphate salt is indispensable for the adsorption of positively charged PAH and b-PEI onto also positively charged alumina surface. However, divalent sulfate salt did not show the same effect on PAH and b-PEI. Bovine submaxillary mucin (BSM) did not show any lubricating effect probably due to too few anchoring sites. The results in this study are significant in practical applications because aqueous lubrication of alumina-alumina interface has been considered most effective at either acidic or alkaline conditions via electrostatic repulsion between the opposing surfaces, whereas the present study provides an alternative and general means to improve the lubricating properties at neutral $\mathrm{pH}$ conditions.

\section{Acknowledgements}

European Research Council (ERC) (Funding Scheme: ERC Starting Grant, 2010, Project Number 261152) and Danish Council for Independent Research (Funding scheme: Individual Postdoc Grants, Project Number 5054-00161) are greatly acknowledged for their financial supports for this study. 


\section{References}

[1] S. Asanabe, Applications of ceramics for tribological components, Materials \& Design, 9 (1988) 253-262.

[2] K. Kato, Tribology of Ceramics, Wear, 136 (1990) 117-133.

[3] P. Andersson, P. Lintula, Load-Carrying Capability of Water-Lubricated Ceramic Journal Bearings, Tribol Int, 27 (1994) 315-321.

[4] K. Kato, Tribology of ceramics and hard coatings, Materialwiss. Werkstofftech., 34 (2003) 1003-1007.

[5] J. Sato, M. Shima, M. Takeuchi, Fretting Wear in Seawater, Wear, 110 (1986) 227-237.

[6] C. Brookes, M. Fagan, R. James, J. McConnachie, The selection and performance of ceramic components in a sea-water pump, in: Proceedings of the JFPS International Symposium on Fluid Power, 1996, pp. 3-12.

[7] Y. Cai, X. Yin, S. Fan, L. Zhang, L. Cheng, Tribological behavior of three-dimensional needled ceramic modified carbon/carbon composites in seawater conditions, Compos. Sci. Technol., 87 (2013) 50-57.

[8] N. Liu, J. Wang, B. Chen, F. Yan, Tribochemical aspects of silicon nitride ceramic sliding against stainless steel under the lubrication of seawater, Tribol Int, 61 (2013) 205-213.

[9] J. Lancaster, A review of the influence of environmental humidity and water on friction, lubrication and wear, Tribol Int, 23 (1990) 371-389.

[10] K. Komvopoulos, H. Li, The effect of tribofilm formation and humidity on the friction and wear properties of ceramic materials, Journal of tribology, 114 (1992) 131-140.

[11] A. Unsworth, Tribology of artifical hip joints, Proceedings of the Institution of Mechanical Engineers, Part J: Journal of Engineering Tribology, 220 (2006) 711-718.

[12] K. Knahr, Tribology in total hip arthroplasty, Springer Science \& Business Media, 2011.

[13] H. Tomizawa, T. Fischer, Friction and wear of silicon nitride and silicon carbide in water: hydrodynamic lubrication at low sliding speed obtained by tribochemical wear, ASLE transactions, 30 (1987) 41-46.

[14] T. Fischer, W. Mullins, Chemical aspects of ceramic tribology, The Journal of Physical Chemistry, 96 (1992) 5690-5701.

[15] T. Saito, Y. Imada, F. Honda, An analytical observation of the tribochemical reaction of silicon nitride sliding with low friction in aqueous solutions, Wear, 205 (1997) 153-159.

[16] H.C. Wong, N. Umehara, K. Kato, Frictional characteristics of ceramics under water-lubricated conditions, Tribol. Lett., 5 (1998) 303-308.

[17] D.A. Rani, Y. Yoshizawa, H. Hyuga, K. Hirao, Y. Yamauchi, Tribological behavior of ceramic materials ( $\mathrm{Si}_{3} \mathrm{~N}_{4}, \mathrm{SiC}$ and $\mathrm{Al}_{2} \mathrm{O}_{3}$ ) in aqueous medium, J. Eur. Ceram. Soc., 24 (2004) 3279-3284.

[18] D. Rani, Y. Yoshizawa, M. Jones, H. Hyuga, K. Hirao, Y. Yamauchi, Comparison of Tribological Behavior Between $\alpha$-Sialon/ $/ \mathrm{Si}_{3} \mathrm{~N}_{4}$ and $\mathrm{Si}_{3} \mathrm{~N}_{4} / \mathrm{Si}_{3} \mathrm{~N}_{4}$ Sliding Pairs in Water Lubrication, J. Am. Ceram. Soc., 88 (2005) 1655-1658.

[19] W. Chen, Y. Gao, F. Ju, Y. Wang, Tribochemical behavior of Si3N4-hBN ceramic materials with water lubrication, Tribol. Lett., 37 (2010) 229-238.

[20] H. Yamakiri, S. Sasaki, T. Kurita, N. Kasashima, Effects of laser surface texturing on friction behavior of silicon nitride under lubrication with water, Tribol Int, 44 (2011) 579-584.

[21] Y. Wang, L. Wang, Q. Xue, Improvement in the tribological performances of $\mathrm{Si}_{3} \mathrm{~N}_{4}, \mathrm{SiC}$ and WC by graphite-like carbon films under dry and water-lubricated sliding conditions, Surf. Coat. Technol., 205 (2011) 2770-2777.

[22] B. Phillips, J. Zabinski, Ionic liquid lubrication effects on ceramics in a water environment, Tribol. Lett., 17 (2004) 533-541. 
[23] Z. Mu, F. Zhou, S. Zhang, Y. Liang, W. Liu, Effect of the functional groups in ionic liquid molecules on the friction and wear behavior of aluminum alloy in lubricated aluminum-on-steel contact, Tribol Int, 38 (2005) 725-731.

[24] W. Hartung, A. Rossi, S. Lee, N.D. Spencer, Aqueous Lubrication of $\mathrm{SiC}$ and $\mathrm{Si}_{3} \mathrm{~N}_{4}$ Ceramics Aided by a Brush-like Copolymer Additive, Poly(L-lysine)-graft-poly(ethylene glycol), Tribol. Lett., 34 (2009) 201-210.

[25] R. Gates, M. Hsu, E. Klaus, Tribochemical mechanism of alumina with water, Tribol. Trans., 32 (1989) 357-363.

[26] M. Kalin, S. Novak, J. Vižintin, Wear and friction behavior of alumina ceramics in aqueous solutions with different $\mathrm{pH}$, Wear, 254 (2003) 1141-1146.

[27] G.V. Franks, L. Meagher, The isoelectric points of sapphire crystals and alpha-alumina powder, Colloids and Surfaces A: Physicochemical and Engineering Aspects, 214 (2003) 99-110.

[28] S. Novak, M. Kalin, The effect of $\mathrm{pH}$ on the wear of water-lubricated alumina and zirconia ceramics, Tribol. Lett., 17 (2004) 727-732.

[29] M. Kalin, S. Novak, J. Vižintin, Surface charge as a new concept for boundary lubrication of ceramics with water, J. Phys. D: Appl. Phys., 39 (2006) 3138.

[30] S. Lee, N.D. Spencer, Poly(L-lysine)-graft-poly(ethylene glycol): a versatile aqueous lubricant additive for tribosystems involving thermoplastics, Lubr. Sci., 20 (2008) 21-34.

[31] J. Yan, X. Zeng, T. Ren, E. van der Heide, Exploring an alternative aqueous lubrication concept for biomedical applications: Hydration lubrication based on $\mathrm{O} / \mathrm{W}$ emulsions combined with graphene oxide, Biosurface and Biotribology, 1 (2015) 113-123.

[32] W. Hartung, T. Drobek, S. Lee, S. Zürcher, N.D. Spencer, The influence of anchoring-group structure on the lubricating properties of brush-forming graft copolymers in an aqueous medium, Tribol. Lett., 31 (2008) 119-128.

[33] M. Alexander, G. Beamson, C. Blomfield, G. Leggett, T. Duc, Interaction of carboxylic acids with the oxyhydroxide surface of aluminium: poly(acrylic acid), acetic acid and propionic acid on pseudoboehmite, J. Electron. Spectrosc. Relat. Phenom., 121 (2001) 19-32.

[34] S. Chibowski, E.O. Mazur, J. Patkowski, Influence of the ionic strength on the adsorption properties of the system dispersed aluminium oxide-polyacrylic acid, Mater. Chem. Phys., 93 (2005) 262-271.

[35] D. Santhiya, S. Subramanian, K. Natarajan, S. Malghan, Surface chemical studies on the competitive adsorption of poly(acrylic acid) and poly(vinyl alcohol) onto alumina, J. Colloid Interface Sci., 216 (1999) 143-153.

[36] S. Novak, M. Kalin, T. Kosmac, Chemcial aspects of wear of alumina ceramics, Wear, 250 (2001) 318-321.

[37] R. Bansil, B.S. Turner, Mucin structure, aggregation, physiological functions and biomedical applications, Curr. Opin. Colloid Interface Sci., 11 (2006) 164-170.

[38] J.A. Greenwood, J.B.P. Williams, Contact of Nominally Flat Surfaces, Proc R Soc Lon Ser-A, 295 (1966) 300-319. The contact pressure in the worn interface was calculated from the average of radius of the wear spot on an alumina sphere after sliding. The average radius was $331 \mu \mathrm{m}$. For rough contacts only the upper most ca. $25 \%$ of the asperities are in contact with the counter face. Greenwood (1966). By bearing analysis of tapping mode AFM images thus gives a real area of fraction of 0.085 compared to apparent area of contact. I.e. the pressure $(P)$ can be estimated: $P=$ $10 \mathrm{~N} /\left((331 \mu \mathrm{m})^{2} \cdot \pi \cdot 0.085\right) \cong 342 \mathrm{MPa}$.

[39] A. Sondag, M. Raas, P. Van Velzen, Contamination of aluminium oxide surfaces in ambient air investigated by FTIR MSR and TOF SIMS. Chemisorption of aliphatic carboxylic acids, Chem. Phys. Lett., 155 (1989) 503-510. 
[40] M.R. Alexander, S. Payan, T.M. Duc, Interfacial interactions of plasma-polymerized acrylic acid and an oxidized aluminium surface investigated using XPS, FTIR and poly(acrylic acid) as a model compound, Surf. Interface Anal., 26 (1998) 961-973.

[41] CRC Handbook of Chemistry and Physics, 89 ed., Taylor and Francis Group LLC, 2009.

[42] D. Santhiya, G. Nandini, S. Subramanian, K. Natarajan, S. Malghan, Effect of polymer molecular weight on the absorption of polyacrylic acid at the alumina-water interface, Colloids and Surfaces A: Physicochemical and Engineering Aspects, 133 (1998) 157-163.

[43] S.S. Shiratori, M.F. Rubner, pH-dependent thickness behavior of sequentially adsorbed layers of weak polyelectrolytes, Macromolecules, 33 (2000) 4213-4219.

[44] M.A. Plunkett, A. Feiler, M.W. Rutland, Atomic force microscopy measurements of adsorbed polyelectrolyte layers. 2. Effect of composition and substrate on structure, forces, and friction, Langmuir, 19 (2003) 4180-4187.

[45] S. Lee, M. Muller, R. Heeb, S. Zurcher, S. Tosatti, M. Heinrich, F. Amstad, S. Pechmann, N.D. Spencer, Self-healing behavior of a polyelectrolyte-based lubricant additive for aqueous lubrication of oxide materials, Tribol. Lett., 24 (2006) 217-223.

[46] A.M. Blokhus, K. Djurhuus, Adsorption of poly(styrene sulfonate) of different molecular weights on $\alpha$-alumina: Effect of added sodium dodecyl sulfate, J. Colloid Interface Sci., 296 (2006) 64-70.

[47] S. Lee, M. Müller, M. Ratoi-Salagean, J. Vörös, S. Pasche, S.M. De Paul, H.A. Spikes, M. Textor, N.D. Spencer, Boundary lubrication of oxide surfaces by poly(L-lysine)- $g$-poly(ethylene glycol)(PLL-g-PEG) in aqueous media, Tribol. Lett., 15 (2003) 231-239.

[48] S.S. Perry, X.P. Yan, F.T. Limpoco, S. Lee, M. Muller, N.D. Spencer, Tribological Properties of Poly(L-lysine)-graft-poly(ethylene glycol) Films: Influence of Polymer Architecture and Adsorbed Conformation, ACS Appl. Mater. Interfaces, 1 (2009) 1224-1230.

[49] T. Røn, I. Javakhishvili, S. Hvilsted, K. Jankova, S. Lee, Ultralow Friction with Hydrophilic Polymer Brushes in Water as Segregated from Silicone Matrix, Adv Mater Interfaces, (2015).

[50] L. Wang, V.A. Bloomfield, Osmotic pressure of polyelectrolytes without added salt, Macromolecules, 23 (1990) 804-809.

[51] C.B. Stanley, H.H. Strey, Measuring osmotic pressure of poly(ethylene glycol) solutions by sedimentation equilibrium ultracentrifugation, Macromolecules, 36 (2003) 6888-6893.

[52] M. Lundin, T. Sandberg, K.D. Caldwell, E. Blomberg, Comparison of the adsorption kinetics and surface arrangement of "as received" and purified bovine submaxillary gland mucin (BSM) on hydrophilic surfaces, J. Colloid Interface Sci., 336 (2009) 30-39.

[53] J.B. Madsen, K.I. Pakkanen, S. Lee, Thermostability of bovine submaxillary mucin (BSM) in bulk solution and at a sliding interface, J. Colloid Interface Sci., 424 (2014) 113-119.

[54] J. Choi, M.F. Rubner, Influence of the degree of ionization on weak polyelectrolyte multilayer assembly, Macromolecules, 38 (2005) 116-124.

[55] P. Patnaik, Handbook of inorganic chemicals, McGraw-Hill New York, 2003.

[56] M.-A. Coletti-Previero, A. Previero, Alumina-phosphate complexes for immobilization of biomolecules, Anal. Biochem., 180 (1989) 1-10.

[57] K. Lutz, C. Gröger, M. Sumper, E. Brunner, Biomimetic silica formation: analysis of the phosphate-induced self-assembly of polyamines, PCCP, 7 (2005) 2812-2815.

[58] A. Shkilnyy, A. Friedrich, B. Tiersch, S. Schöne, M. Fechner, J. Koetz, C.-W. Schläpfer, A. Taubert, Poly(ethylene imine)-controlled calcium phosphate mineralization, Langmuir, 24 (2008) 2102-2109.

[59] I.M. Hutchings, Tribology: friction and wear of engineering materials, 1st ed., Butterworth Heinemann, 1992. 
[60] A. Katchalsky, P. Spitnik, Potentiometric Titrations of Polymethacrylic Acid, J Polym Sci, 2 (1947) 432-446.

[61] T. Fischer, Z. Zhu, H. Kim, D. Shin, Genesis and role of wear debris in sliding wear of ceramics, Wear, 245 (2000) 53-60.

[62] S. Chaiwan, M. Hoffman, P. Munroe, Investigation of sliding wear surfaces in alumina using transmission electron microscopy, Science and Technology of Advanced Materials, 7 (2006) 826833. 